\title{
RESEARCH ON CROWN \& FLATNESS ALLOCATION STRATEGY OF HOT ROLLING MILLS
}

\author{
Sun, W. Q. ; Li, B. ${ }^{* *}$; Shao, J.* \& He, A. R. \\ *Engineering Research Institute, University of Science and Technology Beijing, Beijing 100083, China \\ ** CRRC Qishuyan Institute Co., Ltd, Changzhou 213000, China \\ E-Mail:wqsun18@163.com,ustbshao@163.com, harui@ustb.edu.cn
}

\begin{abstract}
In order to present the reasonable crown of hot rolling mills, the bend force and shift position should be pre-computed in a reasonable manner, while maintaining a good profile. How to search the optimal crown trajectory in ratio crown range is the key problem. Crown and flatness allocation strategy is researched based on dynamic programming method which has been improved and optimized by the algorithm. The key parameters have been calculated by finite element method and regression calculation method, which can regress the equation of the mechanical crown. Comparing with a real production hot rolling mills, the result of state transition equation shows a perfect availability. Additionally, the parallel computing model and look-up table method have been utilized in dynamic programming calculation program. The results show that the bend force normalization population standard deviation fell from 0.2 to 0.06 and the continuously variable crown (CVC) roll shift position normalization population standard deviation fell from 0.3 to 0.15 . The consequences show that the crown and flatness allocation strategy has a better application effect and the computing time is only $16 \mathrm{~ms}$, which proves that the model can be applied online.

(Received, processed and accepted by the Chinese Representative Office.)
\end{abstract}

Key Words: Hot Rolled Strip, Profile, Allocation Strategy, Finite Element Method, Rapid Dynamic Programming

\section{INTRODUCTION}

Profile setup model is the core of the strip shape control system, its computational accuracy and control strategy directly affects the final quality of the rolled strips. In order to improve the control quality of the profile control models, scholars have done much study on the models, including coupling deformation of roller and strip, roller thermal expansion and wear model, etc., all of which have achieved comparatively good verification effect [1-5]. However, the crown initialization problem has drawn little attention. How to improve the allocation strategy in the preset model is becoming an urgent research subject.

In traditional profile preset models, crown initial allocations are based on Shohet theoretical. Many researchers put forward the allocation strategy proportional crown variation with the attenuation coefficient [6-8]. Peng et al. [9] and Kitagoh et al. [10] describe the calculation of compatible crown cone (Shohet crown cone + mechanical crown cone) of each stand, and correct the crowns at inlets and outlets of each stand, respectively. Then the crown allocation is considered based on the relationship between adjacent stands. Liu [11] compares and analyses the hot rolling mathematical models of various western companies, and found that there is still lacking optimization allocation model in the strategic models of real production plants. Liu et al. [12] and Hao et al. [13] conduct the parameter optimization on the multi-variable system of profile control model according to finite element analysis. However, it still adopts traditional models on allocation strategies. Jelali et al. [14] study the profile control strategy of cold rolling mill according to the influence function method, but it did not resolve the crown allocation problem of continuous rolling mills. It is clear that in terms of the present research conditions, the calculation termination conditions before outputting each stand crown are determined by model settings, such as the number of 
iterations, whether shift position and bend force exceed the limitations, whether there is any profile defect and among others, but there is no optimization process during calculation. Those distributions will cause the bend force and shift position approach limiting values, which largely reduce the online control capability, and requires higher performance of machinery. One of the causes for this problem is lack of optimizing computation strategy.

As there are many profile influencing factors during the continuous rolling process, the control model is very complicated and how to improve the model under multi-parameters conditions has become a crucial point. Meanwhile, although finite element-based high precision model can accurately simulate the rolling process, the computation time is very long, which makes it difficult for an online application. Under these circumstances, how to improve the computation speed also becomes a crucial point of the research $[15,16]$. In order to solve the problem in the current profile control model, the initial setting is very simple. Lacking an optimization module, and meanwhile considering the above mentioned two crucial points, this article puts forward a computation model which is suitable for hot rolling crown allocation, and it makes optimization computation based on the improved dynamic programming method. Thus, it determines the optimal crown allocation strategy in crown cone, and creates conditions for the realization of online control.

\section{BASIC IDEA OF DYNAMIC PROGRAMMING METHOD}

The basic dynamic programming is based on the optimization principle, and achieves the search of overall optimal solution. The precondition is the stages having no after-effect; namely, for the state of a certain given stage, the states of previous stages cannot directly affect its subsequent determination, which only depends on its current state $[17,18]$.

In terms of hot rolling plant, the root cause for crown variance is the plastic deformation of the strip, while for single stand, the decisive factor of material deformation when applying load only relates to the stand itself rather than other stands. This means the "stages" of continuous mill plant has no after-effect. Based on this precondition, the dynamic programming-based profile allocation strategy can be established.

\section{PROFILE DISTRIBUTION MODEL}

\subsection{Dynamic programming-based crown allocation model}

The dynamic programming-based crown allocation model is as follows:

(1) Stage: a 7 stand hot rolling mill is taken as the research target, the state number, $i=1 \sim 7$.

(2) State: the inlet crown of each stage, which can be expressed as:

$$
C_{i \mathrm{H}}=\left\{C_{i \mathrm{H} 1}, C_{i \mathrm{H} 2}, \cdots \cdots, C_{i \mathrm{HN}}\right\}
$$

where, $C_{i \mathrm{H}}$ - the inlet crown of stand $i, \mu \mathrm{m}$.

(3) Decision: decision variables are all affecting factors of crown after rolling, expressed as:

$$
u_{i}\left(C_{i \mathrm{H}}\right)=\left\{\begin{array}{l}
P_{i}\left(C_{i \mathrm{H}}\right), F_{\mathrm{b} i}\left(C_{i \mathrm{H}}\right), F_{\mathrm{si}}\left(C_{i \mathrm{H}}\right), \\
D_{\mathrm{w} i}\left(C_{i \mathrm{H}}\right), D_{\mathrm{b} i}\left(C_{i \mathrm{H}}\right), C_{\mathrm{mul} i}\left(C_{i \mathrm{H}}\right)
\end{array}\right\}
$$

where, $P_{i}\left(C_{i \mathrm{H}}\right)$ - decision variable of rolling force,

$F_{\mathrm{b} i}\left(C_{i \mathrm{H}}\right), F_{\mathrm{s} i}\left(C_{i \mathrm{H}}\right)$ - decision variable of work roll bend force and shift position,

$D_{\mathrm{w} i}\left(C_{i \mathrm{H}}\right), D_{\mathrm{b} i}\left(C_{i \mathrm{H}}\right)$ - decision variable of work roll and support roll diameter,

$C_{\mathrm{mul} i}\left(C_{i \mathrm{H}}\right)$ - decision variable of comprehensive profile.

(4) State transition equation: the transition from inlet to outlet crown of each stand,

$$
C_{(i+1) \mathrm{H}}=T_{i}\left\{C_{i \mathrm{H}}, u_{i}\right\}
$$


(5) Strategy: the outlet crown meets the optimal solution of each stand; the strategy table from first stand outlet crown to finish mill outlet crown is as follows:

$$
p_{07}\left(C_{0}\right)=\left\{\begin{array}{l}
u_{1}\left(C_{1 \mathrm{H}}\right), u_{2}\left(C_{2 \mathrm{H}}\right), u_{3}\left(C_{3 \mathrm{H}}\right), \\
u_{4}\left(C_{4 \mathrm{H}}\right), u_{5}\left(C_{5 \mathrm{H}}\right), u_{6}\left(C_{6 \mathrm{H}}\right), \\
u_{7}\left(C_{7 \mathrm{H}}\right)
\end{array}\right\}
$$

where, $C_{0}$ - incoming crown of finish mill, $\mu \mathrm{m}$.

(6) Indicator function: stage indicator function is expressed as:

$$
J_{i}=\alpha\left(\frac{F_{\mathrm{b}}-F_{\mathrm{b} 0}}{F_{\mathrm{b} \max }}\right)^{2}+\beta\left(\frac{F_{\mathrm{s}}-F_{\mathrm{s} 0}}{F_{\mathrm{s} \max }}\right)^{2}+\gamma\left(\frac{C_{i \mathrm{H}}}{H_{i}}-\frac{C_{i \mathrm{~h}}}{h_{i}}\right)^{2}
$$

where, $F_{\mathrm{b}}, F_{\mathrm{b} 0}-$ real and setting value of work roll bend force, $\mathrm{kN}$,

$F_{\mathrm{s}}, F_{\mathrm{s} 0}-$ real and setting value of work roll shift position, mm,

$F_{\text {bmax }}, F_{\text {smax }}-$ maximum value of work roll bending and shift position, mm,

$\alpha, \beta, \gamma$ - weight coefficients.

According to the above mathematical model, the iterative calculative relationship is established according to the principle of optimality, so as to find the optimal strategy.

\subsection{Determination of state transition equation}

\section{Mathematical model of state transition equation}

State transition is an essential aspect of the dynamic programming model, showing the relationship between two states of adjacent stages. In the rolling process means the relationship between the inlet and outlet crown of each stand. The state transition equation is as follows:

$$
C_{\mathrm{h}}=(1-\eta) C+\eta \frac{h}{H} C_{\mathrm{H}}
$$

where, $C_{\mathrm{H}}, C_{\mathrm{h}}, C$ - strip inlet crown, outlet crown and mechanical crown, $\mu \mathrm{m}$,

$\eta$ - crown genetic factor, which adopts the calculation method [19].

The calculation relationship about mechanical crown is defined as follows:

$$
C=f\left(P, F_{\mathrm{s}}, F_{\mathrm{b}}, B, D_{\mathrm{w}}, D_{\mathrm{b}}, C_{\mathrm{mul}}\right)=\frac{P}{K}+K_{\mathrm{b}}\left(F_{\mathrm{b}}-F_{\mathrm{b} 0}\right)+K_{\mathrm{s}}\left(F_{\mathrm{s}}-F_{\mathrm{s} 0}\right)+K_{\mathrm{mul}} C_{\mathrm{mul}}+W
$$

In Eq. (7), $K=f_{1}\left(B, D_{\mathrm{w}}, D_{\mathrm{b}}\right), K_{\mathrm{b}}=f_{2}\left(B, D_{\mathrm{w}}, D_{\mathrm{b}}\right), K_{\mathrm{s}}=f_{3}(B), K_{\mathrm{mul}}=f_{4}(P, B)$, where, $P,-$ rolling force, $\mathrm{kN}$,

$F_{\mathrm{b}}-$ work roll bend force, $\mathrm{kN}$,

$F_{\mathrm{s}}-$ work roll shift position, mm,

$B$ - strip width, mm,

$D_{\mathrm{w}}, D_{\mathrm{b}}$ - diameter of work roll and support roll, $\mathrm{mm}$,

$C_{\text {mul 1 }}$ - equivalent crown of comprehensive profile of work roll, $\mu \mathrm{m}$,

$W-$ constant term,

$K-$ roll stiffness, $\mathrm{kN} \cdot \mu \mathrm{m}^{-1}$,

$K_{\mathrm{b}}, K_{\mathrm{s}}$ - influence coefficient of work roll bend force and roll shift position,

$K_{\text {mul }}$ - influence coefficient of comprehensive profile equivalent crown,

$f_{1}-$ roll stiffness function,

$f_{2}, f_{3}, f_{4}$ - influence coefficient function of work roll bend force, shift position and comprehensive profile crown.

The relationship of comprehensive profile equivalent crowns of work roll, including wear roll equivalent crown $C_{\text {wear }}$ and hot roll profile equivalent crown $C_{\text {thermal }}$, are as follows:

$$
C_{\text {mul }}=C_{\text {wear }}+C_{\text {thermal }}
$$


Wear equivalent crown $C_{\text {wear }}$ and thermal equivalent crown $C_{\text {thermal }}$ can be obtained through the calculation of $C_{\mathrm{mul} 1}$ and $C_{\mathrm{mul}} 2$ respectively; taking the point $40 \mathrm{~mm}$ from strip edge as the reference point for equivalent crown calculation, and the calculation method is as follows:

$$
\begin{gathered}
C_{\text {wear }}=C_{\text {mul 1 }}^{0}-\frac{C_{\text {mul 1 }}^{-40}+C_{\text {mul 1 }}^{40}}{2} \\
C_{\text {thermal }}=C_{\text {mul } 2}^{0}-\frac{C_{\text {mul } 2}^{-40}+C_{\text {mul } 2}^{40}}{2}
\end{gathered}
$$

where, $C_{\text {mul } 1}^{0}$ and $C_{\text {mul } 2}^{0}-$ roll profile of strip centreline,

$C_{\text {mul } 1}^{-40}$ and $C_{\text {mul } 2}^{-40}$ - roll profile close to the drive side,

$C_{\text {mul } 1}^{40}$ and $C_{\text {mul } 2}^{40}-$ roll profile close to operation side.

The calculation of $C_{\mathrm{mul}} 1$ is as follows [20]:

$$
\begin{gathered}
C_{\mathrm{mul} 1}=\left[\sum_{i=1}^{n} \alpha\left(\frac{P_{i}}{B_{i} l_{i}}\right)^{\beta}\left(r_{i} l_{i}\right)^{\gamma} \frac{L_{i}}{\pi\left[D_{i}+2 Y(x+s)\right]} \delta_{i}(x \pm s)\right] \\
\delta_{i}(x \pm s)=\left\{\begin{array}{l}
1 ; \quad-\frac{B_{i}}{2} \leq x \pm s \leq \frac{B_{i}}{2} \\
0 ; \quad-\frac{B_{i}}{2}>x \pm s>\frac{B_{i}}{2}
\end{array}\right. \\
\quad l=\sqrt{\frac{D}{2} r H} \\
Y(x \pm s)=a_{0}(x \pm s)^{3}+a_{1}(x \pm s)^{2}+a_{2}(x \pm s)
\end{gathered}
$$

where, $r$ - pass reduction,

$D$ - roll diameter, $\mathrm{mm}$,

$H$ - strip thickness, mm,

$\delta$ - step function,

$s$ - work roll shift position, $\mathrm{mm}$,

$\alpha, \beta, \gamma$ - function coefficients, where $\alpha=10^{-10}, \beta=0.188$ and $\gamma=0.11$,

$Y-\mathrm{CVC}$ curve equation,

$a_{0}, a_{1}, a_{2}$ - polynomial coefficients.

The method described in references [21-23] is used for the calculation of $C_{\mathrm{mul} 2}$ :

$$
C_{\mathrm{mul} 2}=4(1+v) \frac{\xi}{R} \int_{0}^{R}\left[T(x, r, t)-T_{0}\right] \cdot r \cdot d r
$$

where, $R$ - work roll radius, $\mathrm{mm}$,

$T_{0}$ - initial temperature of work roll, ${ }^{\circ} \mathrm{C}$,

$\xi, v$ - linear expansion coefficient and Poisson's ratio,

$T(x, r, t)$ - the temperature calculation function.

\section{Establishment of finite element model}

In order to obtain the function expressions of $f_{1}, f_{2}, f_{3}$ and $f_{4}$, the physical parameters of a hot roll mill production line is taken of a certain factory as the reference to establish a high precision finite element model. Then the specific form is obtained of the corresponding functions through the analysis of resulting data as well as regression calculation method, thus the state transition equation is determined. The model parameters are shown in Table I.

The work roll profile curve is CVC as shown in Fig. 1.

Based on ABAQUS software, the solid units of work roll and support roll are established according to practical dimensions. The overall roll system needs to be considered and the mesh detailing method is adopted for the contact portion between the strip and roll, so that the computational accuracy of the model can be ensured [24]. 
Table I: Finite element model parameter list.

\begin{tabular}{|c|c|c|c|}
\hline \multirow{2}{*}{ Model parameters } & \multicolumn{3}{|c|}{ Stand No. } \\
\hline & F1-F2 & F3-F4 & F5-F7 \\
\hline Work roll diameter $(\mathrm{mm})$ & $820-950$ & $660-750$ & $540-620$ \\
\hline Support roll diameter $(\mathrm{mm})$ & $1350 \sim 1500$ & \multicolumn{2}{|c|}{$1370 \sim 1500$} \\
\hline Work roll neck diameter $(\mathrm{mm})$ & 500 & 500 & 400 \\
\hline Support roll neck diameter (mm) & \multicolumn{3}{|c|}{900} \\
\hline Work roll barrel length (mm) & \multicolumn{3}{|c|}{2000} \\
\hline Support roll barrel length (mm) & \multicolumn{3}{|c|}{1800} \\
\hline Maximum rolling force $(\mathrm{kN})$ & 44000 & 42000 & 32000 \\
\hline Maximum work roll bend force $(\mathrm{kN})$ & \multicolumn{3}{|c|}{11000} \\
\hline Roll shifting range (mm) & \multicolumn{3}{|c|}{$-100 \sim 100$} \\
\hline Load centre distance $(\mathrm{mm})$ & \multicolumn{3}{|c|}{2900} \\
\hline Mill product width specification $(\mathrm{mm})$ & \multicolumn{3}{|c|}{$900 \sim 1550$} \\
\hline
\end{tabular}

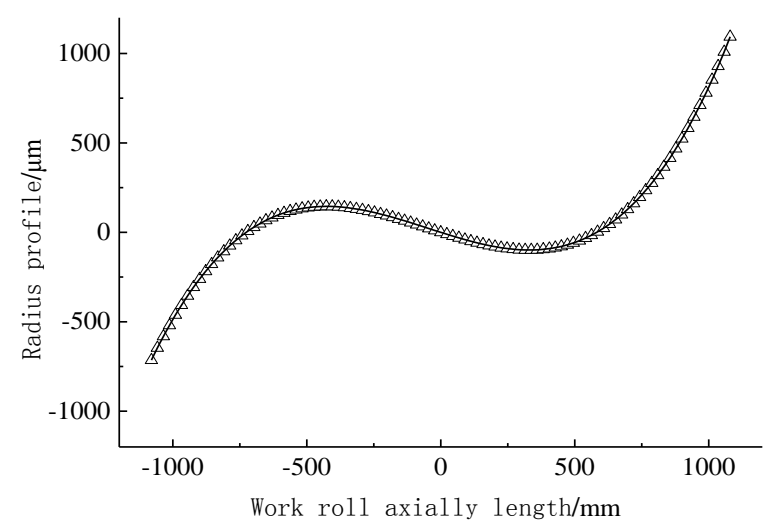

Figure 1: CVC work roll profile curve.

Both rolls and strips adopt 3D deformable solid units, and rolling force and work roll bend force are applied to the model according to practical loading positions. The following assumptions are made:

(1) Roll surface is free from the effect of pitting, peeling and lubrication conditions;

(2) Both the rolls and rolling strips are isotropic materials, and the same parts have uniform mass density distribution and material properties;

(3) The rolling strips are free from external strain and internal initial stress.

The established finite element model is shown in Fig. 2.

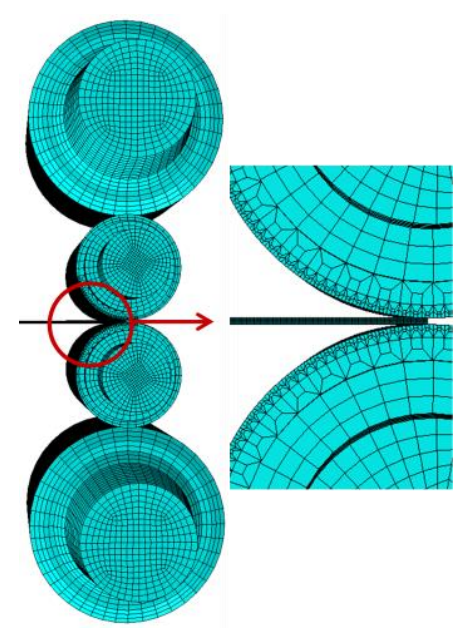

Figure 2: 3D finite element model of CVC 4-roll mill. 


\section{Regression based on the calculation result of finite element model}

(1) Regression calculation of roll stiffness $K$

Figs. $3 \mathrm{a}, \mathrm{b}, \mathrm{c}$ and $\mathrm{d}$ show that when rolls of different dimensions are combined, the transverse stiffness and strip width of the rolls show a non-linear function relation. When the diameters of work rolls and support rolls are determined, transverse stiffness and strip width show a sixth function relation; therefore, $K$ is described, as follows:

$$
K=a_{1} x^{6}+a_{2} x^{5}+a_{3} x^{4}+a_{4} x^{3}+a_{5} x^{2}+a_{6} x+a_{0}
$$

where, $x$ - strip width direction coordinate, $\mathrm{mm}$,

$a_{0}, a_{1}, a_{2}, a_{3}, a_{4}, a_{5}, a_{6}-$ polynomial coefficients.

Figs. 3 e and $\mathrm{f}$ show the change in stiffness when only the work roll or support roll diameter is changed on the premise that strip width is determined. There is a linear relationship between transverse stiffness and roll diameter.

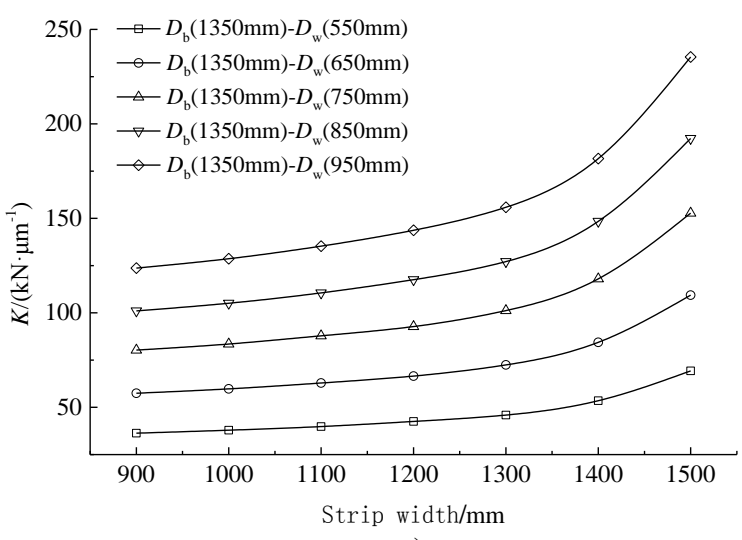

a)

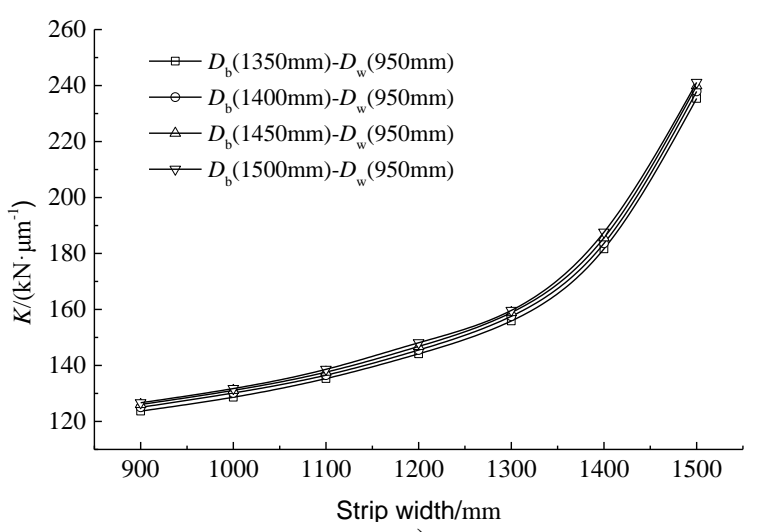

c)

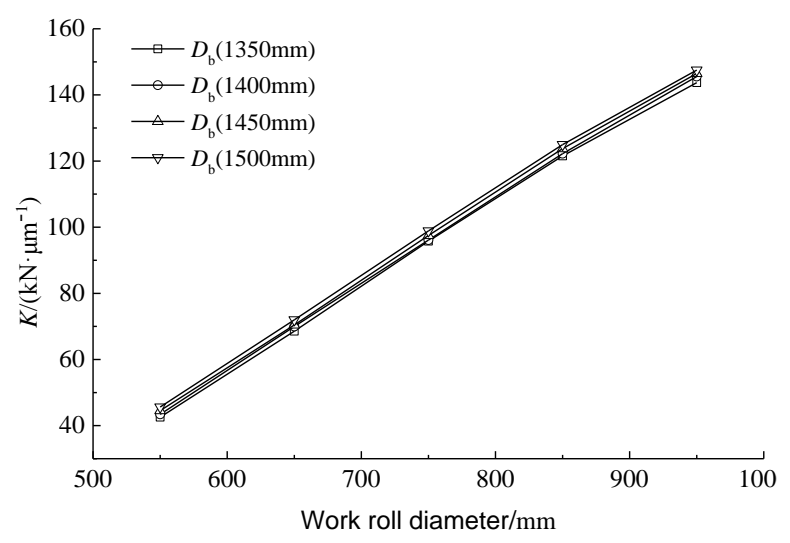

e)

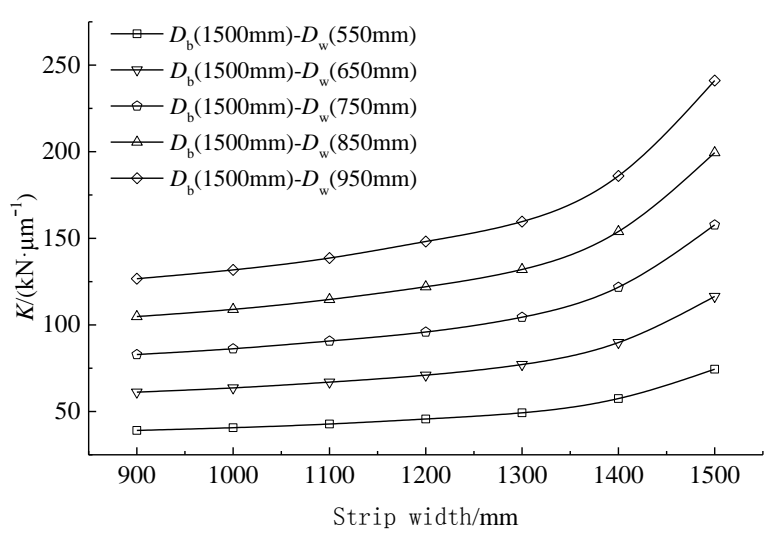

b)

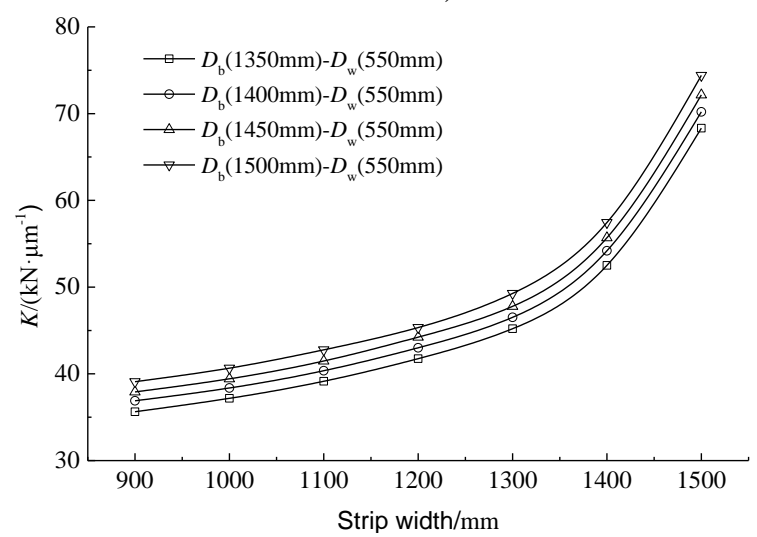

d)

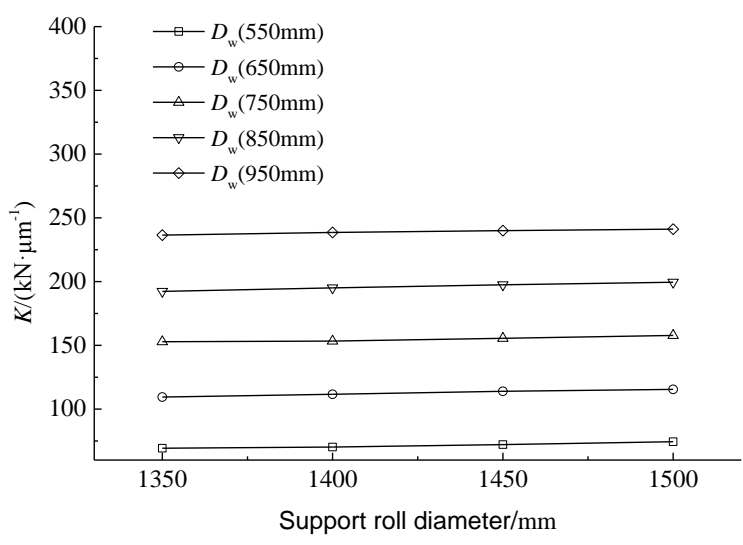

f)

Figure 3: Relationship diagram of influence factors on work roll stiffness. 
As Fig. 3 e shows, with the work roll diameter fixed, the support roll diameter $D_{\mathrm{b}}$ changes has little impact on the stiffness of the roller system, demonstrating that the change of support roll diameter has little impact. Fig. $3 \mathrm{f}$ shows that, with the support roll diameter fixed, the work roll diameter has a large impact on the stiffness of the roll system. In addition, Figs. 3 a and $3 \mathrm{~b}$ show the conditions when only the work roll diameter changes, and the layout of curves are comparatively dispersed. Figs. $3 \mathrm{c}$ and $3 \mathrm{~d}$ show when the support roll diameter is changed, and the layout of curves is comparatively intensive, which proves that the change of the work roll diameter has a larger impact on the stiffness of the roll system than the change of the support roll diameter. Meanwhile, as the maximum variance of the support roll diameter is about $13 \%$, the work roll diameter reaches up to $42 \%$, meaning that the work roll diameter plays a much more important role in affecting the stiffness of the roll system.

The above analysis shows the following:

(1) The replacement of work roll has a large impact on the stiffness of the overall roll system, and during the establishment of the finite element model, the requirement of the amount of work rolls is obviously higher than that of the amount of support rolls. Furthermore, in order to establish models with higher regression calculation accuracy in the simulation analysis of overall roll system, $25 \mathrm{~mm}$ and $50 \mathrm{~mm}$ are used as the changing step of the work roll diameter and the support roll diameter, respectively.

(2) Regression calculation of the influence coefficient $K_{\mathrm{b}}$ of work roll bend force is as follows.

The work roll bend force influence coefficient reflects the relationship between the change of the work roll bend force and the crown of the roll system, reflecting the stiffness of the roll system. Its function variance is the same as the work roll transverse stiffness, and its regression result is still described with the sixth function. The $K_{\mathrm{b}}$ is detailed as follows:

$$
K_{\mathrm{b}}=b_{1} x^{6}+b_{2} x^{5}+b_{3} x^{4}+b_{4} x^{3}+b_{5} x^{2}+b_{6} x+b_{0}
$$

where, $b_{0}, b_{1}, b_{2}, b_{3}, b_{4}, b_{5}, b_{6}$ - polynomial coefficients.

(3) Regression calculation of the influence coefficient $K_{\mathrm{s}}$ of roll shifting

$K_{\mathrm{s}}$ is described with the first-order function as follows:

$$
K_{\mathrm{s}}=c_{1} x+c_{0}
$$

where, $c_{0}, c_{1}$ - function coefficients.

(4) Determination of the influence coefficient $K_{\text {mul }}$ of comprehensive profile equivalent crown is as follows. The physical meaning $K_{\text {mul }}$ is the change rate of the equivalent crown in various working conditions of different roll diameters, rolling force, strip width and others, according to the result of the element model. The regression equation is as follows:

$$
K_{\mathrm{mul}}=\left(k_{1} \cdot D_{b}+k_{2} \cdot D_{w}+C_{1}\right)\left(k_{3} \cdot P \cdot B^{4}+C_{3}\right)
$$

where, $k_{1}, k_{2}, k_{3}$ - model coefficients,

$C_{1}, C_{2}$ - constant terms.

\section{Verification of the accuracy of state transition equation}

The accuracy of the state transition equation directly affects the accuracy and usability of the dynamic programming model. In order to verify whether the mathematical description is correct, the article randomly selects the rolling parameters of 100 strips of a real hot rolling plant as the verification samples of the optimization model, and uses the state transition equation determined above to calculate the outlet crown of each stand, then compares the calculation results with practical outlet crowns. The deviations are shown in Table II.

Table II: Deviations of outlet crowns.

\begin{tabular}{|l|c|c|c|c|}
\hline Deviation range & $<5 \%$ & $5 \% \sim 10 \%$ & $10 \% \sim 15 \%$ & $>15 \%$ \\
\hline Probability & $29.7 \%$ & $59.9 \%$ & $10.4 \%$ & 0 \\
\hline
\end{tabular}


According to statistical result, nearly $90 \%$ of the deviations are within $10 \%$, and the other deviations are within $10 \%$ to $15 \%$. Take the requirement of optimal outlet crown as an example, when the optimal value is $45 \mu \mathrm{m}$, the allowable range of outlet crown deviation is $\pm 20 \mu \mathrm{m}$, with a deviation range up to $44.4 \%$, which is far larger than the maximum deviation $15 \%$ of the established model; this proves that the established state transition equation not only can accurately describe the state transition, but also has practical application value.

\section{IMPROVED RAPID DYNAMIC PROGRAMMING METHOD}

\subsection{Rapid calculation of state transition relationship}

The above state transition equation shows that the crown state has six decisive variables of each stand, which are rolling force, work roll bend force, roll shift position, comprehensive roll profile, support roll and work roll diameter. As dynamic programming is an overall optimization calculation, each variable must be dispersed into $N$ discrete values within their ranges in the process of programming implementation. When roll diameters are fixed, the other four decisive variables together determine the mechanical crown of the mill. The discrete points of four variables are set as $N_{\mathrm{p}}, N_{\mathrm{b}}, N_{\mathrm{s}}, N_{\text {mul }}$, then four-layer cyclic calculation will be needed to cover all combinations of different decisive variables during the process of algorithm implementation. The calculation frequency is $S=N_{\mathrm{p}} \cdot N_{\mathrm{b}} \cdot N_{\mathrm{s}} \cdot N_{\mathrm{mul}}$. Then each stand must be calculated in sequence, thus 28 cycles and $28 \cdot S$ calculations. Furthermore, the state transition function is a high-order polynomial function, and will greatly increase the calculation costs of computer resources. In order to solve this problem, the rapid dynamic programming method based on the model characteristics is proposed.

According to the state transition relationship described above, some pre-computation are made on the mills with different combinations of roll diameters. In view of the initial rolling conditions with inlet thickness $H$, inlet crown $C_{\mathrm{H}}$ and outlet thickness $h$, the strip outlet crown is calculated when rolling force is $P$, work roll bend force is $F_{\mathrm{b}}$, roll shift position is $F_{\mathrm{s}}$ and comprehensive roll profile equivalent crown is $C_{\text {mul }}$, respectively, and the result is recorded in state matrix corresponding to $C_{\mathrm{h}}$. The mathematical meaning of state matrix $U=\left[P, F_{\mathrm{b}}, F_{\mathrm{s}}, C_{\mathrm{mul}}\right]$ is $R=\left[H, h, C_{\mathrm{H}}\right]$ in the initial conditions. The mapping of matrix $U$ is the outlet crown $C_{\mathrm{h}}$. The mapping relationship between $U$ and $C_{\mathrm{h}}$ is a "many-to-one" relationship, and in order to transform it into a "one-to-one" relationship, all crown values shall be recorded with the processing method shown in Fig. 4:
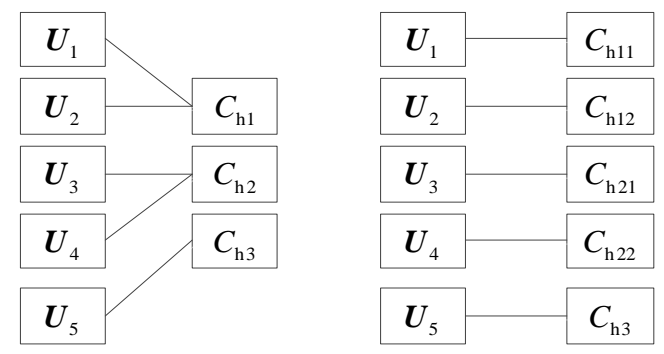

Figure 4: Mapping relationship processing diagram.

In the above mapping diagram, $C_{\mathrm{h} 1}=\left\{C_{\mathrm{h} 11} C_{\mathrm{h} 12}\right\}, C_{\mathrm{h} 2}=\left\{C_{\mathrm{h} 21} C_{\mathrm{h} 22}\right\}$ and $C_{\mathrm{h} 3}=\left\{C_{\mathrm{h} 3}\right\}$. The outlet crown is screened according to the Shohet discriminant, but all outlet crown values in the flat dead area remain. The initial conditions $R=\left[H, h, C_{\mathrm{h}}\right]$ are changed in turn and the strip outlet crown set is calculated under the action of matrix $U$, then the mapping relationship is processed. All the states in the form of matrix are recorded and saved into the database.

In the initialization process of dynamic programming, data from the database is accessed for the first stand according to the calculation result of continuous mill plant load allocation. 
Then all outlet crowns are selected that meet the condition of $R=\left[H, h, C_{\mathrm{h}}\right]$, and are recorded as the outlet state matrix for the first stand. For the second to seventh stands, all outlet crowns that meet the condition of $R R=[H, h]$ are selected and then correction calculation of adjacent stand crowns are conducted, so that the outlet crown range of the previous stand can be equal to the outlet crown range of the next stand. The outlet crown range of the previous stand is recorded as $\left[C_{i \mathrm{H}}^{U}, C_{i \mathrm{H}}^{D}\right]$, and the outlet crown range of next stand as $\left[C_{i+1, \mathrm{~h}}^{U}, C_{i+1, \mathrm{~h}}^{D}\right]$, and the calculation sequence is from the first stand to the seventh stand. The crown ranges after correction are marked as $\left[C_{i \mathrm{H}}^{* U}, C_{i \mathrm{H}}^{* D}\right]$ and $\left[C_{i+1, \mathrm{~h}}^{* U}, C_{i+1, \mathrm{~h}}^{* D}\right]$, and the principle and method of correction are as follows:

$$
\begin{aligned}
& \left\{\begin{array}{ll}
C_{i \mathrm{H}}^{*}=C_{i \mathrm{H}}^{U}, & C_{i+1, \mathrm{~h}}^{* D}=C_{i \mathrm{H}}^{D} \\
C_{i \mathrm{H}}^{* D}=C_{i \mathrm{H}}^{D}, & C_{i+1, \mathrm{~h}}^{* D}=C_{i \mathrm{H}}^{D}
\end{array} \quad \text { where } C_{i \mathrm{H}}^{U}<C_{i+1, \mathrm{~h}}^{D} \quad \text { and } C_{i \mathrm{H}}^{D}>C_{i+1, \mathrm{~h}}^{D}\right. \\
& \left\{\begin{array}{l}
C_{i \mathrm{H}}^{* U}=C_{i+1, \mathrm{~h}}^{U}, C_{i+1, \mathrm{~h}}^{* U}=C_{i+1, \mathrm{~h}}^{U} \\
C_{i \mathrm{H}}^{* D}=C_{i \mathrm{H}}^{D}, \quad C_{i+1, \mathrm{~h}}^{* D}=C_{i \mathrm{H}}^{D}
\end{array} \quad \text { where } C_{i \mathrm{H}}^{U}>C_{i+1, \mathrm{~h}}^{U} \quad \text { and } C_{i \mathrm{H}}^{D}>C_{i+1, \mathrm{~h}}^{D}\right. \\
& \left\{\begin{array}{ll}
C_{i \mathrm{H}}^{* U}=C_{i+1, \mathrm{~h}}^{U}, & C_{i+1, \mathrm{~h}}^{* U}=C_{i+1, \mathrm{~h}}^{U} \\
C_{i \mathrm{H}}^{* D}=C_{i+1, \mathrm{~h}}^{D}, & C_{i+1, \mathrm{~h}}^{* D}=C_{i+1, \mathrm{~h}}^{D}
\end{array} \quad \text { where } C_{i \mathrm{H}}^{U}>C_{i+1, \mathrm{~h}}^{U} \quad \text { and } C_{i \mathrm{H}}^{D}<C_{i+1, \mathrm{~h}}^{D}\right. \\
& \left\{\begin{array}{l}
C_{i \mathrm{H}}^{* U}=C_{i \mathrm{H}}^{U}, \quad C_{i+1, \mathrm{~h}}^{* U}=C_{i \mathrm{H}}^{U} \\
C_{i \mathrm{H}}^{* D}=C_{i+1, \mathrm{~h}}^{D}, \quad C_{i+1, \mathrm{~h}}^{* D}=C_{i+1, \mathrm{~h}}^{D}
\end{array} \quad \text { where } C_{i \mathrm{H}}^{U}<C_{i+1, \mathrm{~h}}^{U} \quad \text { and } C_{i \mathrm{H}}^{D}<C_{i+1, \mathrm{~h}}^{D}\right.
\end{aligned}
$$

According to the screening results, the state matrix of is as follows:

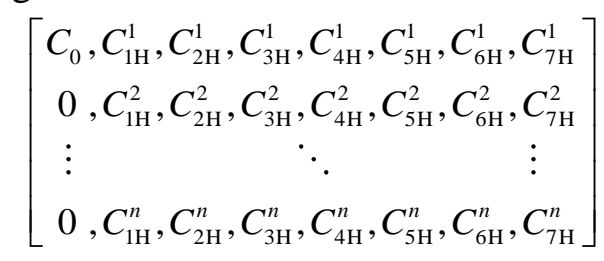

$C_{\text {out }}$ is outlet target crown of the finishing mill. The outlet state is selected as equal to $C_{\text {out }}$ from the outlet crown state set of the $7^{\text {th }}$ stand, and is marked as the end point of the optimization model. The obtained state optimization matrix is as follows:

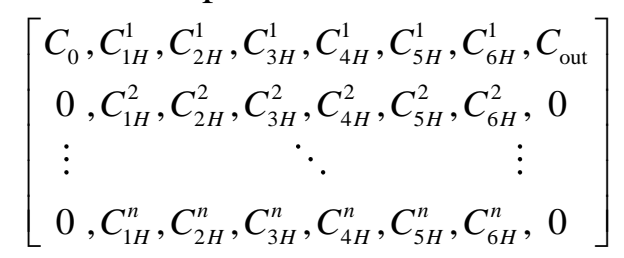

The above-mentioned steps are the determination method of state matrix, where the complex computation of the traditional dynamic programming method can be avoided. There is no high-order polynomial iteration in the initialization data. The state matrix and its corresponding decisive variables can be directly obtained by the table look-up method, which greatly reduces the computation time to meet the realization of online computation.

\subsection{Parallel search}

The solution idea of the dynamic programming method is to transform the multi-stage optimal decision problem into a single stage optimal decision problem. Regarding the models with given inherent starting point (end point), sequential (reverse) recursive algorithm conducts a single step optimization from the starting point (end point) and makes step by step calculation until reaching the end point (starting point), thus completing the optimization calculation. But with the increasing of stage variables and state variables, the optimization speed will sharply fall, lengthening the computation time. In order to solve the problem and increase the 
computation speed, the search method of the dynamic programming model will be improved, so that the computation time can be reduced.

Due to the characteristics of the rolling technology, regarding a certain strip, the inlet crown is a fixed value before finish mills, and the outlet crown is preset, meaning that the starting and ending points of the optimization are both fixed. As known from the principle of optimization of dynamic programming method, the optimal strategy must be the optimal and only solution with fixed starting and ending points, and its sequential optimization result is the same as the result of reverse optimization. On this basis, the single-direction search mode of the traditional dynamic programming method is transformed into the double-direction parallel search method from starting point and ending point at the same time.

The reverse recursion starting from the ending point and boundary condition is as follows:

$$
\begin{gathered}
L_{j}\left(x_{j}\right)=\operatorname{opt}\left\{f_{j}[x(j), u(j)]+L_{j+1}[x(j+1)]\right\}, j=n, n-1, \ldots, 1 \\
\left\{\begin{array}{l}
L_{j=n+1}[x(j+1)]=0 \\
x_{j+1}=T_{j}[x(j), u(j)]
\end{array}\right.
\end{gathered}
$$

The sequential recursion starting from the starting point and boundary condition is as follows:

$$
\begin{gathered}
L_{k}[x(k+1)]=\operatorname{opt}\left\{f_{k}[x(k+1), u(k)]+L_{k-1}[x(k)]\right\}, k=1,2, \ldots, n \\
\left\{\begin{array}{l}
L_{k=0}[x(1)]=0 \\
x(k)=T_{k}[x(k+1), u(k)]
\end{array}\right.
\end{gathered}
$$

where, $x(k), u(k), T(k)$ - state description function, strategy description function, and state transition equation, respectively,

$L[x(k), u(k)]$ - energy needed for state $x(k)$ under the action of strategy $u(k)$.

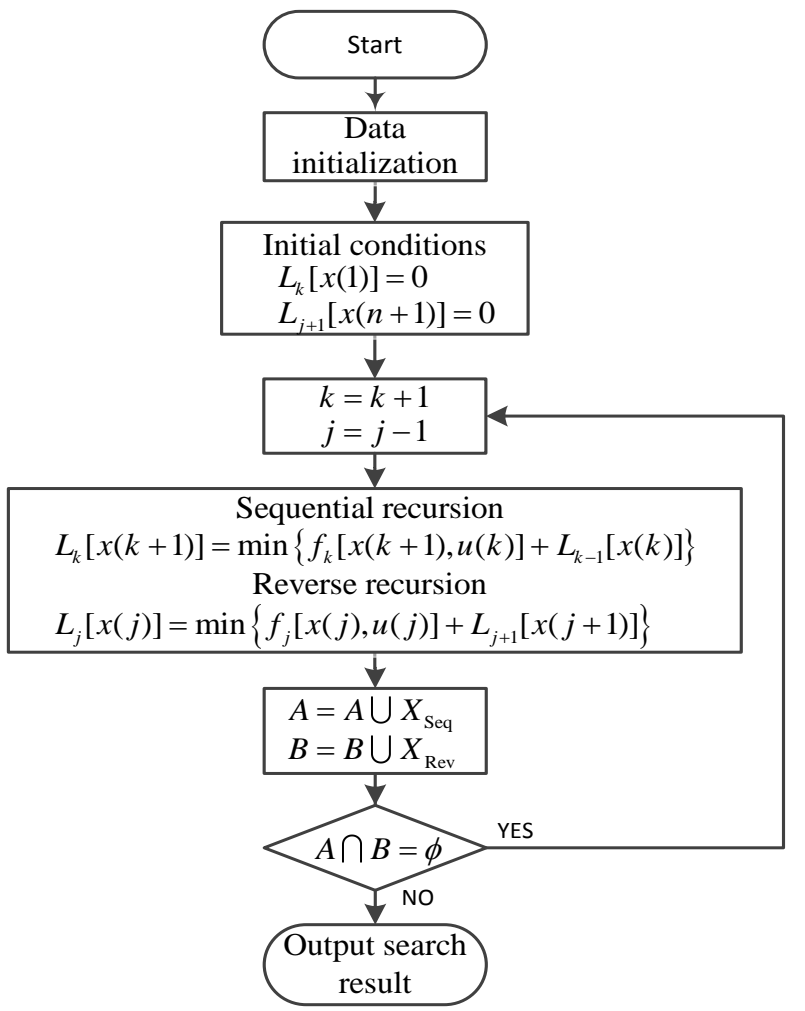

Figure 5: Flow chart of parallel search.

In the flow chart shown in Fig. 5, the double-direction parallel recursion process as follows: 
(1) For the dynamic programming model with the starting point of $P$, ending point of $Q$ and stage number of $N, A$ and $B$ are marked as the starting point and ending point state sets, respectively, and the initialization condition is $A=\{P\}$ and $B=\{Q\}$.

(2) Sequential recursion calculation:

$$
x(k)=\operatorname{opt}\{x(k-1)+L[x(k-1), u(k-1)]\}
$$

Reverse recursion calculation:

$$
x(k)=\operatorname{opt}\{x(k+1)+L[x(k), u(k)]\}
$$

$A=A \cup X_{\text {Seq }}, B=B \cup X_{\mathrm{Rev}}$ and $X_{\mathrm{Seq}}, X_{\mathrm{Rev}}$ separately correspond to the state description sets of sequential recursion and reverse recursion in a certain middle stage.

(3) When sequential and reverse recursions coincide with each other in a certain stage, whether $A \cap B$ is null set $\Phi$ can be determined. If null, re-calculation is needed; otherwise, the output path is the shortest, and the optimal control strategy is obtained.

\section{APPLICATION EFFECT OF PROFILE DISTRIBUTION MODEL}

On the premise of ensuring a good profile, how to reasonably allocate work roll bend force and roll shift position, giving full play to control capacity of each stand while reducing the frequency of limit positions is the problem to be solved. Two parameters of continuous rolling mill plant are used as the standard reference for evaluating whether the model is qualified; standard deviation of normalized work roll bend force $\sigma_{\text {bend }}$ and standard deviation of normalized roll shift position $\sigma_{\text {shift. }}$ The statistical meaning of $\sigma_{\text {bend }}$ and $\sigma_{\text {shift }}$ is the statistical indicator of work roll bend force and shift position diversity of each stand in continuous hot mill plant. The larger the difference between $\sigma_{\text {bend }}$ and $\sigma_{\text {shift }}$ is, the more unbalance of each stand will be, meaning the overall control capability is worse.

Regarding the same strip of a certain hot mill plant, production line real setting model and optimization allocation model are used for the calculation, and the results are compared.

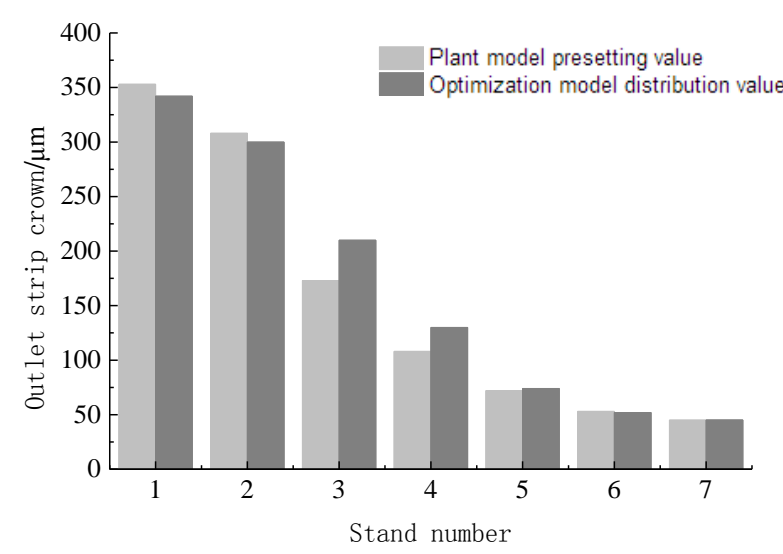

Figure 6: Comparison of crown distribution effects.

The crown distribution result is shown in Fig. 6, in which the $7^{\text {th }}$ stand outlet strip crown is the same, and the proportional crown variance of each stand are within the Shohet proportional crown cone, which proves that the optimization distribution model can completely meet the requirements of outlet crown and ensure a good profile.

The comparisons of work roll bend force and roll shift position is shown in Figs. 7 and 8, showing that the calculation result of optimization distribution model avoids the occurrence of limit positions, and is comparatively balanced. The production line real models without optimization process encounters the occurrence of limit, which proves the optimization distribution model can be applied for practical use. 


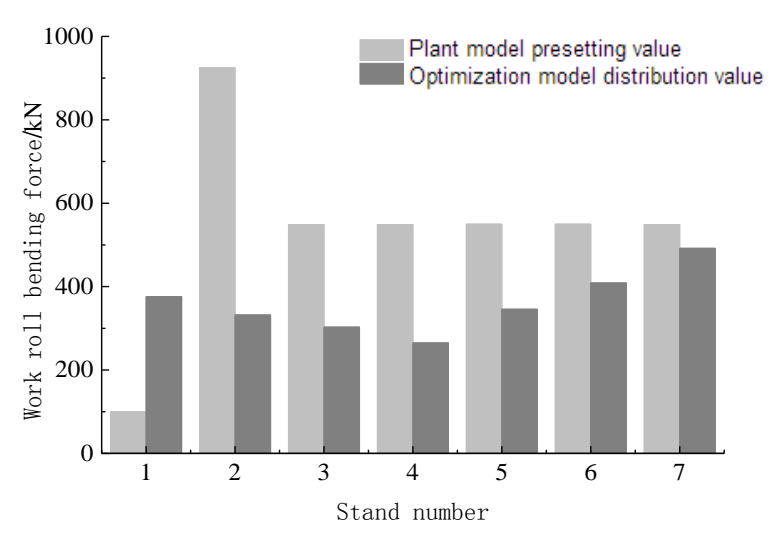

Figure 7: Comparison of work roll bending force allocation effect.

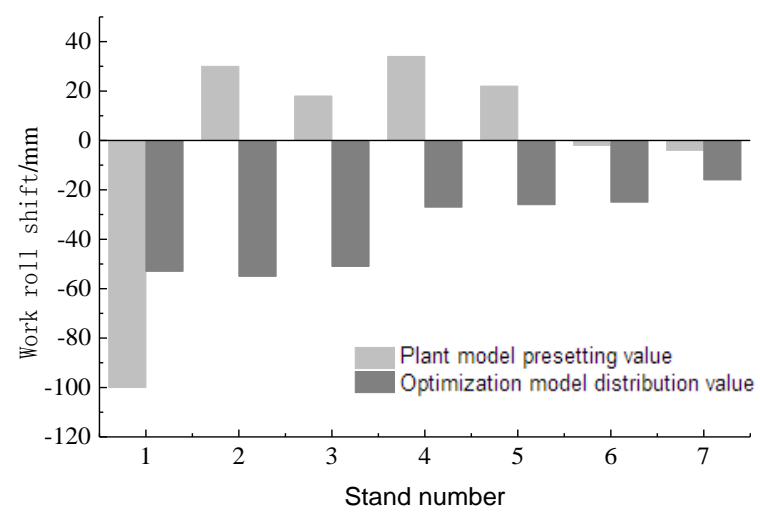

Figure 8: Comparison of shift position allocation effect.

Comparison with the indicator function value is shown in Table III, which clearly shows that the overall optimal search result is better than that of the production line real model.

Table III: Comparison of indicator function values.

\begin{tabular}{|l|c|c|}
\hline Model & Production line model & Optimization distribution model \\
\hline Indicator function value & 1.27 & 0.89 \\
\hline
\end{tabular}

As shown in Table IV, overall standard deviation of normalized work roll bend force declines from 0.2 to 0.06 , and shift position distribution declines from 0.3 to 0.15 , with a declining of up to $70 \%$ and $50 \%$, respectively, showing that the profile control capability is improved.

Table IV: $\sigma_{\text {bend }}$ and $\sigma_{\text {shift }}$ overall standard deviations comparison.

\begin{tabular}{|c|c|c|}
\hline Model & Production line model & Optimization distribution model \\
\hline$\sigma_{\text {bend }}$ & 0.2 & 0.06 \\
\hline$\sigma_{\text {shift }}$ & 0.3 & 0.15 \\
\hline
\end{tabular}

Results of comparison show that the optimization distribution model, under the premise of ensuring a good profile, work roll bend force and shift position avoid the occurrence of limit positions, and the roll shifting and bending settings of each stand are more balanced, which largely improves the online control performance of hot rolling mills. Furthermore, the doubledirection search and look-up table method replacing the quadruple iterative computation, ensures that the computation time is less than $16 \mathrm{~ms}$, which meets online applications

\section{CONCLUSION}

(1) Regarding the crown distribution problem in the initial setting of continuous hot rolling mill, based on a large amount of regression calculation of off-line finite element models, this article conducts the optimization calculation strategy, which accurately describes the state transition, and establishes the dynamic programming-based profile distribution model.

(2) The optimization model ensures the work roll bend force and shift position within a reasonable range, and each stand is distributed uniformly, which makes the layout of bend force and shift position of each stand more balanced, so as to give full play to the profile control capability of the equipment.

(3) The double-direction search computation is proposed. Furthermore, the quadruple iterative computation is replaced by the look-up table method, which greatly improves the efficiency of optimization computation, with a computation time of less than $16 \mathrm{~ms}$ under 
laboratory conditions, which creates favourable conditions for the realization of online computation and has great practical significance.

\section{ACKNOWLEDGEMENT}

This work was supported in part by Doctoral Program Foundation of Institutions of Higher Education of China (No. 20130006120024) and National Natural Science Funds of China (51404021).

\section{REFERENCES}

[1] Fukushima, S.; Washikita, Y.; Sasaki, T.; Nakagawa, S.; Buei, Y.; Yakita, Y.; Yanagimoto, J. (2014). Mixed scheduled rolling of high tensile strength and mild steel using a high-accuracy profile model in hot strip finishing mill, Tetsu-to-Hagane, Vol. 100, No. 12, 1499-1507 (67-75), doi:10.2355/tetsutohagane.100.1499

[2] Kitagoh, K.; Shimoda, N.; Kubo, N. (2012). Development of practical shape models and control system for strips, 2012 IFAC Workshop on Automation in the Mining, Mineral and Metal Industries, 33-38

[3] Mroz, T.; Hearns, G.; Bilkhu, T.; Burnham, K. J.; Linden, J. G. (2008). Predictive profile control for a hot strip mill, Proceedings of the $19^{\text {th }}$ International Conference on Systems Engineering (ICSENG '08), 260-265

[4] Yang, G. H.; Cao, J. G.; Zhang, J.; Li, H. B.; Zheng, J. (2014). Target curve setting model for automatic flatness control on stand 5 of $2180 \mathrm{~mm}$ tandem cold rolling mill, Applied Mechanics and Materials, Vol. 665, 37-41, doi:10.4028/www.scientific.net/AMM.665.37

[5] He, A.-R.; Shao, J.; Ling, Z.; Sun, Z.-J.; Liu, C.-W. (2011). Shape control system of $1580 \mathrm{~mm}$ hot strip mills, Iron \& Steel, Vol. 46, No. 3, 47-50

[6] Hacquin, A.; Lasserre, R. (2002). New-generation crown and flatness set-up model for hot mills, Revue de Metallurgie. Cahiers D'Informations Techniques, Vol. 99, No. 7-8, 639-646

[7] Salimi, M.; Forouzan, M. R. (2002). Determination of bending actuators set points to control crown and flatness in hot rolling of strip, Journal of Materials Processing Technology, Vol. 125126, 670-677, doi:10.1016/S0924-0136(02)00342-4

[8] Sato, M.; Kuchi, M.; Honjo, H.; Abe, Y. (2004). Strip crown and flatness control for hot strip mill, Ishikawajima Harima Engineering Review, Vol. 44, No. 5, 352-357

[9] Peng, K.-X.; Zhong, H.; Zhao, L.; Xue, K.; Ji, Y.-D. (2014). Strip shape modeling and its setup strategy in hot strip mill process, The International Journal of Advanced Manufacturing Technology, Vol. 72, No.5-8, 589-605, doi:10.1007/s00170-014-5649-2

[10] Kitagoh, K.; Shimoda, N.; Kubo, N. (2012). Development of practical shape models and control system for strips, Proceedings of the 2012 IFAC Workshop on Automation in the Mining, Mineral and Metal Industries, 38-43

[11] Liu, W.-Z. (2013). Comparison and analysis of the foreign companies' mathematical model for HSM, Metallurgical Industry Automation, Vol. 37, No. 5, 5-11

[12] Liu, Z. Y.; Sun, Y. G.; Song, X. R. (2014). Algorithm optimization of shape setup calculation in hot strip mill, Advanced Materials Research, Vol. 926, 3364-3367, doi:10.4028/ www.scientific.net/AMR.926-930.3364

[13] Hao, L.; Di, H. S.; Gong, D. Y.; Wei, D. B.; Jiang, Z. Y. (2013). Advanced flatness control strategies for multivariable optimisation flatness control system of foil rolling mill, Advanced Materials Research, Vol. 655, 1450-1455, doi:10.4028/www.scientific.net/AMR.655-657.1450

[14] Jelali, M.; Wolff, A.; Kipper, H.; Schiller, M. (2003). Improved flatness in EKO's tandem cold mill, Metallurgical Research \& Technology, Vol. 100, No. 10, 987-992, doi:10.1051/ metal:2003116

[15] Kong, F.-F.; He, A.-R.; Shao, J.; Ge, X.-Y. (2014). Finite element model for rapidly evaluating the thermal expansion of rolls in hot strip mills, Journal of University of Science and Technology Beijing, Vol. 36, No. 5, 674-679

[16] Kong, F. F.; He, A. R.; Shao, J. (2012). Research on rapid online calculation methods of roll stack deformation, Journal of Mechanical Engineering, Vol. 48, No. 2, 121-126 
[17] Ohno, K.; Boh, T.; Nakade, K.; Tamura, T. (2015). New approximate dynamic programming algorithms for large-scale undiscounted Markov decision processes and their application to optimize a production and distribution system, European Journal of Operational Research, Vol. 249, No. 1, 22-31, doi:10.1016/j.ejor.2015.07.026

[18] Regmi, R. K.; Jung, K. (2016). Application of dynamic programming to locate the critical failure surface in a rainfall induced slope failure problem, KSCE Journal of Civil Engineering, Vol. 20, No. 1, 452-462, doi:10.1007/s12205-015-0183-9

[19] Panjkovic, V.; Fraser, G.; Yuen, D. (2005). Modelling of the strip shape and profile evolution and its applications to hot rolling, South East Asia Iron and Steel Institute Quarterly, Vol. 34, No. 1, 67-74

[20] Serajzadeh, S.; Taheri, A. K. (2004). Modelling work-roll temperature variations in hot strip rolling, International Journal of Modelling \& Simulation, Vol. 24, No. 1, 42-50, doi:10.1080/ $\underline{02286203.2004 .11442286}$

[21] John, S.; Sinkdar, S.; Mukhopadhyay, A.; Pandit, A. (2006). Roll wear prediction model for finishing stands of hot strip mill, Ironmaking \& Steelmaking, Vol. 33, No. 2, 169-175, doi: $10.1179 / 174328106 \times 80091$

[22] Sun, W.-Q.; Shao, J.; He, A.-R.; Zhao, H.-S.; Zhou, J. (2015). Research on residual stress quantitative reduction in laminar cooling on hot strip mill, International Journal of Heat and Technology, Vol. 33, No. 4,19-24, doi:10.18280/ijht.330403

[23] Nikitenko, E. (2008). Flat product rolling \& finishing technologies - Hot band profile irregularities related to thermal contour of work rolls, Iron and Steel Technology, Vol. 5, No. 8, 59-65

[24] Hentati, T.; Dammak, F.; Fakhfakh, T.; Haddar, M. (2005). A finite element development for ball bearing nonlinear stiffness modelization, International Journal of Simulation Modelling, Vol. 4, No. 3, 118-128, doi:10.2507/IJSIMM04(3)2.046 